\title{
Who is your constituency? The political engagement of humanitarian organisations
}

\author{
Christopher Lockyear ${ }^{1 *}$ (D) and Andrew Cunningham²
}

\begin{abstract}
The World Humanitarian Summit of 2016 was an attempt to elevate humanitarian organisations more completely into the international political domain. Humanitarian organisations are agencies which provide life-saving assistance to populations in times of conflict or man-made disasters and use the humanitarian principles of humanity, impartiality, neutrality, and independence to guide their work. However, humanitarian organisations have always been political entities which engage within the political arena that encompasses humanitarian activity and consists of component actors that include beneficiaries, host and donor governments, local communities, and humanitarian organisations themselves. How, and with whom, they engage contributes to their identity and consequently their ability to implement humanitarian activities. The appropriateness of their political engagement, and the impact of such engagement on their identity, is frequently a source of confusion and contention within humanitarian organisations, particularly when it comes to consideration of the neutrality principle. This commentary argues for the value of using the concept of constituency in analysing the political identity of a humanitarian organisation and its process of political engagement. Without proactively analysing their constituencies, humanitarians are not defining their own political identity and risk others defining it for them. It is often feared that by engaging politically, humanitarian organisations risk compromising their neutrality. This assertion, however, wrongly assumes that the principle of political neutrality must be associated with a state of political inactivity. Further, political neutrality, along with other dimensions of political identity, is not a concept that can be maintained passively but must be built and defined in every political context, both to implement the humanitarian agenda and to defend it from co-option. This process requires taking a clear stance aligned with beneficiaries and other allied constituents, building coalitions and constructive positions with them, and countering coercive constituents who act destructively towards humanitarian principles.
\end{abstract}

Keywords: Political engagement, Humanitarian constituency, Neutrality

\section{Introduction}

Humanitarian organisations provide life-saving assistance to populations in times of crises and use the humanitarian principles of humanity, impartiality, neutrality, and independence to guide their work (ICRC 1996). Humanitarian organisations of all types struggle with the concept of political engagement. Engagement implies involvement with other actors, the reverse of isolation. In admitting a relationship or a connection with others, one does not shy away from active participation with themes of concern to other actors. Engagement facilitates differentiating oneself from other actors, identifies similarities with others, and more generally helps to construct the political

\footnotetext{
* Correspondence: chrislockyear@gmail.com

${ }^{1}$ Action Against Hunger, New York, USA

Full list of author information is available at the end of the article
}

environment within which one is working. In establishing who one's friends and enemies are by identifying their political positions relative to one's own, it is possible to engage in an appropriate manner with each and to develop an understanding of the political arena within which one is working. ${ }^{1}$ For a humanitarian organisation, political engagement is a means to an end-to assist with the implementation of humanitarian programmes and reduce the efficacy of the direct drivers of human suffering.

Taking a specific political stance is not the goal, but rather to constructively engage with political actors with a clear humanitarian objective in mind. This is a difficult, and sometimes risky, path to navigate and takes discipline and coordination in a world where the political manipulation of aid by states and intergovernmental organisations is widespread and may be at odds with the 
interests of aid recipients or the institutional interests of aid organisations themselves.

For some organisations, it is an existential question whether political engagement aligns with the humanitarian imperative. For others, political engagement is a given and the question is how to engage with the wide variety of relevant actors working in the humanitarian arena, such as militaries, terrorist organisations, politicians and political parties, governments, and other aid actors, including the United Nations (UN) and donors. This commentary argues that political engagement is not only appropriate but that humanitarian organisations must engage politically to properly fulfil their mandates and to maintain their identity.

\section{Political engagement}

Clearly, International Non-Governmental Organisations (INGOs) must negotiate access within a political arena filled with multiple actors, including beneficiaries, host and donor governments, local communities, and humanitarian organisations themselves. Within this arena, aid gets shaped through the interactions between these multiple actors (Hilhorst and Jansen 2010: 1121). For example, aid workers must obtain permission to implement activities from the political authorities, including fulfilling administrative procedures such as obtaining visas and other permits and organising the importation of supplies and establishing proper communications (Warner 1999). A variety of political actors must be influenced concerning policy issues affecting humanitarian organisations, such as NGO laws, although political engagement should not be confused with advocacy ${ }^{2}$ activities or a theory of change ${ }^{3}$ framework. Both are simply tools within the wider domain of political engagement, which is inclusive of an organisation's action and presence, such as the implementation of aid programmes, negotiations to reach populations requiring aid, the acceptance of funding, and organisational reputation. These elements interact within a political context-within the community of states, intergovernmental organisations, local administrations, and informal power structures. Within this environment states (Yale Law School 2001) and the UN (United Nations General Assembly 2015), as well as regional military alliances such as the North Atlantic Treaty Organisation (NATO) (CBC News 2010), steer the delivery of aid to their own political advantage. The instrumentalism of aid, however, is not our primary concern, rather the political motivations and actions of humanitarian organisations themselves and the tools which they use to achieve these objectives.

Humanitarian organisations, therefore, must be nuanced, informed, and strategic in analysing the political context as well as the political implications of their work and should also engage other actors politically for increased impact. Importantly, to be effective, engagement should be proactive and by choice, rather than limited to a reactive response, such as adapting to changing legal or bureaucratic requirements, as the former is a negotiation and the latter adherence to a rule. For example, choosing to engage with a political party on the government's humanitarian policies is proactive engagement whilst quietly fulfilling the requirements of a bureaucratic rule out of fear of legal repercussions is simply adherence. Political engagement can be positive, constructive, and cooperative in manner, or at variance with external actors' views and actions through advocating for change, or even condemning the policies and actions of other actors. Political engagement can also take the form of proactive disengagement, for example Médecins Sans Frontières' (MSF) decision to not attend the 2016 World Humanitarian Summit (Parker 2016).

Political engagement, therefore, should be thought of as the proactive, conscious interaction between humanitarian organisations and institutions or groups holding power over the content and implementation of the humanitarian agenda and the people aid is meant to serve. But if this is true, does not this way of looking at humanitarian action contradict the principle of neutrality, that is, that humanitarian organisations should not engage in controversies of 'a political nature'?

Political neutrality, as defined in International Humanitarian Law, indicates non-participation in hostilities, including not engaging in political controversies (Plattner 1996). This way of conceptualising neutrality still applies and has lost none of its vigour. Indeed, humanitarian organisations should not take decisions based on the political interests of belligerents, or in view of the interests of their proxies, as this would contravene this fundamental humanitarian principle. The neutrality principle, however, is itself an exposed political position, as 'despite the pronouncements and practices of humanitarian actors seeking to ensure that their actions confer no military advantage, and are driven solely on the basis of need, the humanitarian principles of neutrality and impartiality are under constant assault' (Curtis 2001: 3). For example, the peace imperative is conflated with the humanitarian imperative resulting in the withholding of aid, as the UK government was accused of in Sierra Leone in 1997 and Afghanistan from 1996 (Macrae 2000: 4).

Based on this analysis of political engagement within a humanitarian arena filled with multiple actors, we propose a way to think about engaging with these political actors through the concept of 'constituency'.

\section{What is a constituency?}

When thinking about the concept of constituency, it is usually in the democratic electoral sense, i.e. as a body 
of citizens entitled to elect a representative. Broadly speaking, in the humanitarian arena, a constituency can be conceptualised as a group of people, or political entities, sharing similar political views and aspirations, or as the people involved with, or served by, a humanitarian organisation. This definition, however, does not assist in defining an approach to take in engaging with these constituencies. This commentary proposes a multiconstituency and goal-attainment approach to assessing organisational effectiveness and applies it to the humanitarian arena.

In the organisational administration literature, various frameworks are used to study organisational effectiveness. A common framework assumes that an organisation is faced with multiple constituencies and must figure out a way to evaluate its effectiveness in a complex system. The multi-constituency approach argues that it is arbitrary to label one criterion a priori as the correct one because each presents a valid point of view' (Kenis and Provan 2009: 443). Performance is treated 'as a set of several (or perhaps many) statements, each reflecting the evaluative criteria applied by various constituencies involved to a greater or lesser degree with the organization' (Connolly et al. 1980: 213). In this view, as there are many constituencies and an unclear hierarchy, there cannot be one evaluative framework. Performance depends on the questions asked which are dependent on the evaluation criteria most applicable to that constituency. Asking people who only care about fuel efficiency what colour they want their car to be does not help the organisation manufacture a better vehicle for that group. This framework may be viewed as too relativistic than many would feel comfortable with, and therefore, it may be useful to decide which evaluation criteria are the most important to the organisation and set those as the primary goals (Kenis and Provan 2009: 443). This goal-attainment model may be the most useful when considering how a humanitarian organisation faces multiple-constituencies in the arena within which they operate.

For a humanitarian organisation, the primary goal is obviously to offer assistance to those most in need in as principled a manner as possible, and organisational effectiveness is evaluated against this primary goal. The challenge is how to evaluate goal-attainment in relation to engagement with the multiple constituencies in the arena. In this framework, constituency building is a twoway street, as is political action. This approach helps to define the actors that can be constructively dealt with and ones that try to co-opt humanitarian organisations by making them part of their constituency, such as donor governments making funding conditional on recipient humanitarian organisations supporting elements of their foreign policy priorities. Such an arena should be thought of as a matrix of interlocking constituencies, all of which have their own goals in mind. From the perspective of a humanitarian organisation, its primary constituency will of course be the beneficiaries. But when acting in a complex political context, there are others, such as donors, the states which provide legal registration, armed actors which allow operations, or the organisation's staff.

Engaging with a constituency is a choice. Omitting or adding groups from the list is a substantive act. Omitting sympathetic constituents can weaken an appropriate political identity, whilst omitting hostile constituents will strengthen it, and vice versa. It should be remembered that this model describes a two-way street. A humanitarian organisation defines the goals it wants to attain, but so do the other political actors in the arena. Using this multiple-constituency and goal-attainment framework, we define three modes of constituency building: constituency by coercion, constituency by discretion, and constituency by compromise. Each mode must be evaluated by whether this form of constituency building increases organisational effectiveness-helps the organisation to attain its primary goal.

\section{Constituency by coercion}

A constituency by coercion forms when a political actor places itself within the humanitarian organisation's sphere of influence and seeks to persuade the humanitarian organisation to adhere to their goals via force or threats. These constituencies hold the levers of control and manifest a monopoly of violence within the humanitarian arena (in the Weberian sense). Such constituencies could be the apparatus of state or other armed or governing bodies (for example rebel and opposition groups or local authorities). Where coercion is necessary, it can safely be assumed that the constituency's goals are fully or partly at odds with that of the humanitarian organisation.

Practically, a humanitarian organisation chooses, as part of its constituency, political actors which do not align with their political objectives, as without accepting the conditions of these actors the organisation would potentially cease to exist. There are many ways in which aid agencies can be coerced. The two main drivers for this are the heavy donor dependence of most humanitarian organisations and political-bureaucratic constraints in the countries of operation. For example, counterterrorism laws and regulations are a method by which donor organisations force themselves into being part of a humanitarian organisation's constituency (adopt our policy, or do not get our money) (Rieff 2002). As well, they limit the agency of the organisation to choose who else should be in its constituency by restricting organisations with which they may have contact. Further, as a 
constituent, donor governments can have a significant influence over where and how humanitarian organisations run their programmes-reducing their capacity for independent decision making.

In the countries of operation, NGO laws, travel permits, and visa restrictions imposed by the host government all act to force themselves firmly into the humanitarian organisation's constituency. Bureaucracy is not a neutral technology (Bauman 1989: 17). In the clear majority of cases, without legal registration it is not possible for a humanitarian organisation to operate in a country, without visas it is not possible to send international staff to a country, and without travel permits it is not possible to move staff around the country, all heavily, perhaps terminally, impacting an organisation's ability to operate. The political interests of a government could be completely at odds with that of the humanitarian organisation, to the extent that they could themselves be the cause of the needs that compel the humanitarian organisation to be present. Nonetheless, to be able to respond, the humanitarian organisation must accept them into its constituency.

\section{Constituency by discretion}

In this mode, a humanitarian organisation chooses to include political actors as constituents based on the humanitarian organisation's vision and mandate alone, and in doing so does not compromise its principles or endanger its operational or political objectives. The political objectives of these actors align without conflict or contradiction with those of the humanitarian organisation itself.

For example, it is obvious that when politically engaging with other actors a humanitarian organisation does so in reference to the needs of the beneficiaries. In choosing beneficiaries as a constituency, the humanitarian organisation's position is developed around their rights, needs, and desires. In fact, beneficiaries can be considered a humanitarian organisation's primary constituency. A political engagement strategy must maximise the impact of this position, and thus positively benefit these constituents. By acting politically with beneficiaries as a constituency, the humanitarian organisation does not compromise its political neutrality.

Other groups can also be proactively adopted as a constituency. Donors in their role as politically influential actors can also be a discretionary constituency. For example, a donor as a sponsor and therefore supporter of a humanitarian organisation's programmes can be an important ally. They can provide political support when engaging with host governments. The United Nations also has a political role that indicates that it could in certain circumstances be accepted into an organisation's constituency, such as relying on the United Nations Office for the
Coordination of Humanitarian Affairs (UNOCHA) for negotiated access in conflict zones.

The supportive elements of the societies from which a humanitarian organisation arises can also be a positive constituent. Not only is the organisation born of civil society, but civil society and popular opinion can determine governmental policy. This is often a vital constituency to encourage political action on common themes of interest.

\section{Constituency by compromise}

In this mode, a constituency becomes an accepted part of a humanitarian organisation's sphere of influence through a process of agreement that is reached by each side making concessions. The goals of this constituency may not be fully aligned with that of the humanitarian organisation but simultaneously do not directly contravene the humanitarian organisation's mandate of identity. For example, a humanitarian organisation may agree with authority $\mathrm{X}$ to provide services to a population $\mathrm{Z}$ despite their lack of needs to ensure access is gained to population $\mathrm{Y}$ with greater needs. Thus, by gaining the desired access, the humanitarian organisation has compromised absolute impartiality and authority $\mathrm{X}$ has become a constituency by compromise.

An organisation may choose to accept political actors who do not fully align with their political objectives into to their constituency for pragmatic reasons. Such pragmatic reasons should be contrasted with the existential nature of choices compelled through coercion. These choices are most likely to be at the operational level, for example to assist with issues of access or efficiency of response. Not accepting these actors will not have a terminal impact on the organisation, but neither are they fully aligned with the organisation's identity.

Negotiating with non-state armed actors is a prime example of the need for compromise. An organisation desires not only safe access but also to influence the relationship between the armed actors and the population. The point of reference in common is the population. Humanitarian organisations and non-state armed actors certainly do not share the same political objectives but share a relationship with a population, and a certain level of compromise is necessary for all three parties to inhabit the same operational space. In certain circumstances, compromise can obviously turn into coercion, which can lead to omission from the constituency and loss of access.

Another example is when the UN's political involvement in a context makes it a party to the conflict as well as a humanitarian actor. In this case, an organisation's cooperation with the UN's humanitarian agencies must be mediated through distancing from its political mandate. As the two mandates are intimately linked, 
albeit often at cross purposes, there is a need for the UN to be a part of a humanitarian organisation's constituency to defend space for principled humanitarian action.

\section{Summary}

It is entirely possible, in fact likely, that there are multiple and overlapping categories of choice behind each

Table 1 The constituency framework

\begin{tabular}{lll}
\hline Constituency & Inclusion mode & Example \\
\hline $\begin{array}{l}\text { Beneficiaries } \\
\text { (legitimate recipients of aid) }\end{array}$ & $\begin{array}{l}\text { Discretion } \\
\text { A humanitarian organisation actively seeks engagement with } \\
\text { beneficiaries to determine culturally appropriate provision } \\
\text { of services. }\end{array}$
\end{tabular}

Other humanitarian organisations

(organisations working within a similar value framework with complementary or overlapping programmatic implementation capacity)

Regional actors

(governments which are neither donors nor hosts, usually countries with influence over the hosts and with whom a variety of humanitarian organisations routinely engage, e.g.

China, Russia, Iran, and Brazil)

Donor governments

(governments providing funding to humanitarian

organisations, and in doing so sets out a programmatic and geographical prioritisation of aid)

Host governments

(governments holding sovereignty over the territory within which the humanitarian organisation is operating)

Local communities

(formal and informal civil society organisations, representing community interests, who may or may not make up part of the beneficiary group)

Terrorist groups

(groups which use violence against civilians to attain political, religious, or ideological goals)

Home societies

(societies in which the humanitarian organisations are

headquartered and through which private funds are raised and political influence sought)

Staff

(persons contracted by the humanitarian organisation, either in the country of operations or headquarters, to assist in the implementation of the organisation's social mission)
Compromise

Discretion

Compromise

Discretion

Discretion

Coercion

Discretion

Coercion

Discretion

Compromise

Discretion

Coercion

Discretion

Coercion

Discretion

Coercion

Compromise
A humanitarian organisation with nutrition expertise actively seeks an organisation with protection expertise to provide more comprehensive programming in a specific geographical area.

A humanitarian organisation acting as a sub-grantee towards a prime grant holder accepts additional reporting requirements to enter into an operational consortium.

A humanitarian organisation asks for the support of a neighbouring, but more powerful government, to influence the host government to give less restricted access to beneficiaries.

A humanitarian organisation seeks funding from a donor due to the influence it has over the host government; thus, the donor government develops a vested interest in the ability of the humanitarian organisation to continue to provide services and offers political support to the humanitarian organisation.

A donor government insists a humanitarian organisation checks its staff lists against a counter-terrorism database exposing the humanitarian organisation to accusations of spying by local communities.

A humanitarian organisation accepts increasing its response in a country against its own best judgement because of the financial overheads that the humanitarian organisation will receive, allowing it to respond elsewhere.

In an emergency, a host government relaxes import restrictions on humanitarian organisations bringing supplies into its territory.

A host government prevents a humanitarian organisation working in opposition areas from receiving visas for international staff.

A humanitarian organisation seeks input from a community about the most acute areas of need.

A humanitarian organisation agrees to provide services to men in a community, despite their lack of need, to ensure agreement to provide services to women.

A humanitarian organisation may actively seek security assurances from groups labelled as 'terrorists' to ensure safety of staff and beneficiaries.

A terrorist group demands that a humanitarian organisation pays a tax which will be used to fund the conflict.

A humanitarian organisation actively raises awareness of an issue to increase pressure within a home society to encourage their government to act in a particular situation.

A humanitarian organisation is forced to reduce the response to a refugee crisis due to political pressure at home against immigration.

A humanitarian organisation develops an employment policy which facilitates the provision of labour required to implement humanitarian programmes.

A humanitarian organisation is forced to stop programmes due to strikes by staff.

A humanitarian organisation feels compelled to continue to run certain programmes due to historical precedent and emotional attachment by staff. 
constituency. Further, the calculation will change over time as political interests and priorities change. Whom a humanitarian organisation chooses to accept into its constituency necessarily defines its political nature, and the more it is coerced to accept undesirable actors the more it compromises on its political neutrality and its identity as a principled humanitarian actor. The same applies to a lesser extent with compromise, and it is the choice of each individual organisation how far it should go in terms of such compromises. The key point is to explicitly acknowledge whom one chooses as a constituent and why, what this means for oneself as a political actor, and how this effects principled humanitarian action. Not making this analysis risks being naively coopted through coercion.

Table 1 below summarises the findings and provides examples of how different constituencies could be included in the political arena of a humanitarian organisation. This table is not exhaustive in either terms of the inventory of constituencies or their possible inclusion modes. To some degree, all constituencies are likely to employ the full range of inclusion modes. Rather, this table focuses on those inclusion modes that are deemed the most important per constituency, where importance is defined as the sum of likelihood and impact.

\section{Conclusion}

In the post-World Humanitarian Summit world, it is hoped that this constituency framework will be useful to humanitarian organisations in defining and capitalising on their political engagement. Humanitarian organisations should not be fearful of the idea of political engagement. If they hold the concept of political neutrality at their core, it is in fact a duty that they engage.

\section{Endnotes}

${ }^{1}$ For a discussion on the 'friends and enemies' dichotomy and its relation to defining the 'political', see Schmitt (2007).

${ }^{2}$ Advocacy: the act of pleading for, supporting, or recommending; active espousal.

${ }^{3}$ The 'Theory of Change' is a specific type of methodology for planning, participation, and evaluation that is used in the philanthropy, not-for-profit, and government sectors to promote social change.

\section{Abbreviations}

INGO: International Non-Governmental Organisation; MSF: Medecins Sans Frontieres; NATO: North Atlantic Treaty Organisation; UN: United Nations; UNOCHA: United Nations Office for the Coordination of Humanitarian Affairs

\section{Authors' contributions}

$\mathrm{CL}$ and $\mathrm{AC}$ have joint effort in conceptualisation and writing. Both authors read and approved the final manuscript.

\section{Funding}

$\mathrm{N} / \mathrm{a}$

\section{Authors' information}

$\mathrm{N} / \mathrm{a}$

\section{Competing interests}

The authors declare that they have no competing interests.

\section{Publisher's Note}

Springer Nature remains neutral with regard to jurisdictional claims in published maps and institutional affiliations.

\section{Author details}

${ }^{1}$ Action Against Hunger, New York, USA. ${ }^{2}$ Conflict, Security, and Development Research Group, Department of War Studies, King's College London, London, UK.

Received: 21 March 2017 Accepted: 10 October 2017

Published online: 23 October 2017

\section{References}

Bauman Z (1989) Modernity and the holocaust. Cornell University Press, Ithaca CBC News (2010) Afghanistan a Model for Future Crises: NATO, 04 March 2010. https://goo.gl/As9AJy. Accessed 23 Aug 2017

Connolly T, Conlon EJ, Deutsch SJ (1980) Organizational effectiveness: a multiple-constituency approach. Acad Manag Rev 5(2):211-217

Curtis D (2001) Politics and Humanitarian Aid: Debates, Dilemmas and Dissension. HPG Report 10, ODI. https://goo.gl/RqXK9Q. Accessed 23 Aug 2017

Hilhorst D, Jansen B (2010) Humanitarian space as arena: a perspective on the everyday politics of aid. Dev Chang 41(6):1117-1139

ICRC (1996) The Fundamental Principles of the Red Cross and Red Crescent. https://goo.gl/Xj8Yjq. Accessed 23 Aug 2017

Kenis P, Provan KG (2009) Toward an exogenous theory of public network performance. Public Adm 87(3):440-456

Macrae J (2000) The Politics of Coherence: Humanitarianism and Foreign Policy in the Post-Cold War Era. HPG Briefing 1, ODI. https://goo.gl/FiubDL. Accessed 25 Aug 2017

Parker B (2016) MSF pulls out of World Humanitarian Summit. IRIN News, 05 May 2016. https://goo.gl/DUJvjL. Accessed 23 Aug 2017

Plattner D (1996) ICRC Neutrality and Neutrality in Humanitarian Assistance. Int Rev Red Cross (311). https://goo.gl/mwnLo2. Accessed 23 Aug 2017

Rieff D (2002) Humanitarianism in Crisis. Foreign Affairs. November/December 2002. https://goo.gl/Wpa1YP. Accessed 23 Aug 2017.

Schmitt C (2007) The concept of the political. University of Chicago Press, Chicago, pp 26-28

United Nations General Assembly (2015) 'Plan of Action to Prevent Violent Extremism, Report of the Secretary-General'. 24 December 2015. https://goo.gl/XaYds3. Accessed 23 Aug 2017

Warner D (1999) The politics of the political/humanitarian divide. Int Rev Red Cross 833:109-118

Yale Law School (2001) September 11, 2001: Attack on America, Secretary Colin L. Powell, Remarks to the National Foreign Policy Conference for Leaders of Nongovernmental Organizations. The Avalon Project, 26 October 2001. https://goo.gl/WqrWTa. Last accessed 23 Aug 2017

\section{Acknowledgements}

N/a

Availability of data and materials

$\mathrm{N} / \mathrm{a}$ 